Meta

Journal des traducteurs

Translators' Journal

\title{
Projet d'histoire de la traduction et de l'interprétation au Canada
}

\section{Jean Delisle}

Volume 22, numéro 1, mars 1977

Histoire de la traduction au Canada

URI : https://id.erudit.org/iderudit/002530ar

DOI : https://doi.org/10.7202/002530ar

Aller au sommaire du numéro

Éditeur(s)

Les Presses de l'Université de Montréal

ISSN

0026-0452 (imprimé)

1492-1421 (numérique)

Découvrir la revue

Citer cet article

Delisle, J. (1977). Projet d'histoire de la traduction et de l'interprétation au Canada. Meta, 22(1), 66-71. https://doi.org/10.7202/002530ar d'utilisation que vous pouvez consulter en ligne. 


\title{
Projet d'histoire de la traduction et de l'interprétation au Canada*
}

\author{
* Que nous le voulions ou non, nous \\ sommes un peuple de traducteurs. » \\ Léon Lorrain
}

L'histoire de la traduction et de l'interprétation au pays n'a guère retenu l'attention des chercheurs jusqu'ici. Il n'existe à vrai dire sur le sujet que de rares articles souvent superficiels et toujours parcellaires. D'aucuns s'interrogent même sur l'intérêt que présente une telle recherche. Leur scepticisme fait écho à celui de Léon Tolstoï qui estimait que " les historiens répondent à des questions qu'on ne leur a jamais posées ». L'auteur de Guerre et paix n'aurait pas lancé cette boutade sans être convaincu que les réponses apportées à ces questions ne manquent pas, elles, de pertinence puisqu'elles sont riches d'enseignements.

L'omniprésence de la traduction dans la vie quotidienne des Canadiens est sans doute une des caractéristiques dominantes du Canada et notamment du Canada français. Il faudrait vraiment méconnaître la réalité canadienne pour sousestimer la place importante qu'occupe la traduction au pays et les multiples conséquences qui en découlent. Il y a plus de trente ans, Pierre Daviault avait constaté avec beaucoup de justesse que

Les manifestations de l'esprit au Canada se produisent à l'ordinaire dans l'ambiance de la traduction. La pâture intellectuelle du Canadien moyen est faite, pour une très large part, de traduction. Nos journaux reçoivent les dépêches d'agences en anglais; en anglais aussi, le texte des annonces. Nos postes de T.S.F. nous serinent de la traduction à la journée. Orateurs politiques ou sacrés, professeurs, érudits, chercheurs, commerçants ou industriels, avocats ou ouvriers spécialisés, médecins ou ingénieurs, tous, partout et toujours, nous nous servons de textes anglais que nous traduisons ou qu'on traduit à notre intention. La traduction s'infiltre partout, commande chaque geste de notre vie. La langue sera par conséquent, dans une large mesure, ce que sera la traduction ${ }^{\text {. }}$.

Toujours d'actualité, ces lignes sont lourdes de sous-entendus et renferment tout un programme de recherche sur le concept d'identité canadienne et québécoise. En effet, l'étude du phénomène global de la traduction au Canada et de

\footnotetext{
* Les trois personnes suivantes travaillent à ce projet d'histoire de la traduction au Canada : Paul A. Horguelin, professeur à l'Ecole de traduction de l'Université de Montréal, Marc Lebel, du Centre de recherche en eivilisation canadienne-française de l'Université d'Ottawa et enfin l'auteur de cet article qui est professeur à l'Ecole de traducteurs et d'interprètes de l'Université d'Ottawa.

1. Pierre Daviault. * Traducteur's et traduction au Canada *, Mémoires de la Société Royale du Canada, $3 e$ série, tome 38, section I, 1944, p. 67.
} 
ses ramifications psychologiques, sociales, linguistiques et culturelles peut apporter une contribution unique à la connaissance de la civilisation canadienne, et plus particulièrement de la civilisation canadienne-française. La traduction d'un document, d'un ouvrage ou d'une cuvre littéraire n'a qu'un intérêt relativement limité pour l'historien de la traduction - bien qu'il existe de célèbres exceptions, et la traduction de la Bible n'est pas la moindre. Mais replacée dans une perspective historique, l'étude du rôle particulier de la traduction et des traducteurs dans un pays comme le Canada peut donner lieu à une recherche originale. Le sujet est digne d'intérêt et cet article vise à le démontrer en exposant la démarche à suivre pour qu'une telle recherche s'élève au-dessus de la simple critique qualitative des traductions et qu'elle soit un apport valable à la connaissance de la civilisation canadienne.

Dans l'esprit de bien des gens, l'histoire de la traduction est indissociable de l'histoire littéraire. Il est vrai que la traduction " esthétique », c'est-à-dire d'œuvres littéraires et poétiques, est jugée comme la plus belle expression de l'art de traduire et que ce genre (par opposition à la traduction administrative, publicitaire, technico-scientifique ou juridique) retient l'attention des historiens de la littérature dans les pays où la population forme un bloc linguistique relativement homogène, ce qui n'est pas le cas du Canada. Dans ces pays «normaux», comme l'a fait observer Pierre Bourgault lors d'un déjeuner-causerie de la Société des traducteurs du Québec, on traduit pour les siens ce qui a été pensé et conçu par d'autres ou encore on traduit pour d'autres ce qui a été pensé et conçu par les siens. Au Canada, les traducteurs traduisent pour les gens d'ici ce qui a été pensé et conçu ici. Cette observation très juste, qui a le poids d'une boutade cynique, appelle une redéfinition de la traduction et du rôle du traducteur dans le contexte canadien. D'autre part, l'histoire de la traduction chez un peuple qui a une longue histoire nationale et une tradition littéraire s'étendant sur de nombreux siècles

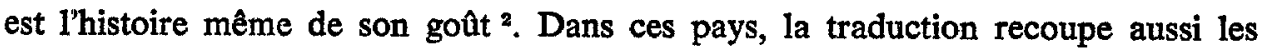
mouvements intellectuels ou religieux, selon les époques; elle en est parfois la manifestation.

La traduction * esthétique » au Canada a toujours été infime comparativement au volume des textes dits * informatifs » ou « utilitaires ». Il n'y a pas eu d'écoles regroupant des traducteurs se réclamant d'un même maître ou professant une conception commune de la traduction. La traduction n'a jamais été non plus au coeur de grandes querelles littéraires comme celles qui ont opposé, en France, Anciens et Modernes au XVIr siècle, et, en Angleterre, partisans du libéralisme intellectuel et adversaires de la Renaissance à l'époque élisabéthaine. Quelques faits récents témoignent cependant de l'essor que connaît la traduction littéraire ${ }^{3}$

2. L'ouvrage remarquable de Roger Zuber, les a Belles Infideles s et la formation du goat classique (Paris, A. Colin, 1968, 503 p.), en donne une démonstration éclatante.

3. Au pays on a même tendance à inclure sous cette désignation les cuvres qui appartiennent à la littérature, aux arts et aux sciences humaines. Voir notamment la \& Bibliographie des livres canadiens en traduction : 1580-1974 * publiée dans Meta (vol. XX, no 1 , p. 83-105) par Maureen Newman et Philip Straford. 
dans un petit pays comme le nôtre et laissent entrevoir un avenir prometteur dans ce domaine *.

Constatant que la traduction littéraire n'est pas aussi florissante que dans d'autres pays, certains concluent, un peu trop hâtivement à mon avis, à la nonpertinence d'une histoire de la traduction au Canada. Depuis la Conquête, la traduction s'étend à tous les secteurs d'activité au pays et c'est pourquoi ce serait une erreur que d'aborder cette recherche d'un point de vue strictement littéraire. Indissociable de la réalité canadienne, la traduction est trop « envahissante * pour être étudiée dans ses seules manifestations artistiques.

L'analyse du phénomène de la traduction dans ses innombrables manifestations doit donc obligatoirement tenir compte du contexte social, économique et politique propre au Québec et au Canada.

Parler de traduction dans l'entreprise publique, a écrit Frédéric Phaneuf, sans parler en même temps du contexte socio-économique dans lequel les traducteurs doivent travailler, ce serait escamoter l'essentiel du problème. Il n'y a traduction valable que si le contexte socio-culturel et l'éclairage de la langue de départ sont remplacés et par le contexte socio-culturel qui sert de soutien à la langue d'arrivée et par l'éclairage particulier à cette langue ${ }^{5}$.

L'historien de la traduction sera donc amené à préciser le rôle et les responsabilités sociales et culturelles des traducteurs en milieu canadien. La recherche s'effectuera sur trois fronts complémentaires : 1) L'historique des professions (traduction/interprétation); 2) La production (aspects quantitatif et qualitatif) ; 3) La traduction, phénomène d'acculturation. Ces trois grandes têtes de chapitre se subdivisent de la façon suivante :

\section{L'historique des professions}

- Origine, évolution, organisation : (traduction/interprétation)

- Sociétés et Associations professionnelles

- Écoles de traducteurs et d'interprètes

- Renouveau terminologique

- Traduction automatique

- Conditions de travail : (reconnaissance professionnelle/pigistes/droit d'auteur/rémunération)

- Figures dominantes

II. La production

- Nature des traductions : - cuvres littéraires

- documents officiels

4. On peut citer notamment : 1) les subventions à la traduction et les prix de traduction du Conseil des arts du Canada ; 2) la création récente de la collection des a Deux solitudes > consacrée exclusivement à la publication de traductions d'ceuvres d'auteurs canadiens-français et canadiens-anglais ; 3) le regroupement en association des traducteurs littéraires du Canada en mai 1975.

5. Frédéric Phaneuf, « La traduction dans les entreprises publiques du Canada *, Meta, vol. XXI, $\mathrm{n}^{\circ} 1$, mars 1976, p. 73 . 
- ouvrages didactiques

- réclame publicitaire

- affichage/étiquetage

- articles de presse

- autres

- Analyses quantitatives 6

- Evaluation qualitative

III. La traduction, phénomène d'acculturation

- Traduction et langue écrite

- Traduction et bilinguisme

- Traduction et publicité

- Traduction et culture : (littérature/théâtre/cinéma/télévision/enseignement)

Le dernier de ces trois volets, la traduction étudiée en tant que phénomène d'acculturation, est sans doute le plus important et le plus intéressant, puisque les données brutes des deux premières divisions acquièrent un sens. L'histoire de la traduction au Canada ne présenterait en effet qu'un intérêt limité si elle ne jetait pas une lumière nouvelle sur le phénomène fort complexe de l'acculturation ${ }^{7}$ au sein d'un pays composé de deux groupes d'origine culturelle différente. La traduction apparaît comme une voie royale pour l'étude des contacts culturels des deux peuples fondateurs qui, pour des raisons historiques bien connues, ont été contraints de partager des frontières nationales communes. Ont-ils cependant trouvé un modus vivendi acceptable pour l'un et l'autre ? La cohabitation a-t-elle joué au détriment d'un des peuples? L'anthropologie culturelle nous enseigne que deux cultures mises en contact agissent et réagissent l'une sur l'autre et que ce processus d'interactions (cross-fertilization) donne lieu à des échanges de traits culturels. Par voie de conséquence, ces échanges engendrent des mutations qui se traduisent parfois par l'émergence d'une culture originale, qui est autre chose qu'une simple juxtaposition ou synthèse de deux cultures. Les Canadiens peuvent-ils prétendre avoir une identité propre et originale qui serait la résultante de la rencontre des cultures anglaise et française?

La traduction est un véhicule privilégié de communication et d'échanges à tous les niveaux de la société canadienne. Elle semble bien avoir été un des principaux supports de la transmission des éléments de culture anglophone au Canada français et particulièrement au Québec. II s'agit de savoir s'il y a eu un courant d'échanges aussi intense dans le sens inverse? Certains en doutent et il

6. La traduction, souvent largement méconnue, semble de plus être inconnue des statisticiens. Apparemment, il n'existe pas de statistiques fournissant les quelques données qui permettraient de mieux évaluer notre secteur. * Roger Boivineau, * Pigistes et bureaux de traduction *, Meta, vol. XXI, no 1, mars 1976, p. 5.

7. Une définition désormais classique de l'acculturation a été donnée en $1938 \mathrm{par} R$. Redfield, R. Linton et M. Herskovits dans leur Memorandum for the Study of Acculturation : - L'acculturation est l'ensemble des phénomènes qui résultent du contact direct et continu entre des groupes d'individus de culture différente, avec des changements subséquents dans les types culturels de l'un ou des deux groupes. : 
s'en trouve même qui vont jusqu'à affirmer que la tracuction est une version moderne du cheval de Troie introduit dans l'enceinte de la culture française en Amérique du Nord. La traduction serait à leurs yeux une "profession coloniale 》, un instrument subtil d'assimilation. Cette opinion présuppose que le Canada est d'abord conçu en anglais, puis traduit pour la collectivité francophone. (Combien de rapports importants émanant du gouvernement fédéral ont d'abord été rédigés en français ?)

Dès le début du régime anglais, le bilinguisme officiel passe par la plume des traducteurs. Les premiers gouverneurs anglais ont eu tôt fait de recruter des "secrétaires-traducteurs \$ pour rendre dans la langue de la majorité le texte des édits et des proclamations promulgı́s par la minorité conquérante. Il s'écoulera de nombreuses années - trop nombreuses aux dires de certains - avant que le bilinguisme se manifeste sous d'autres formes. La pratique intensive de la traduction dans les administrations québécoise et fédérale n'a jamais été abandonnée et rien ne laisse prévoir qu'elle le sera. Tout au contraire. L'histoire de la traduction recoupe donc celle du bilinguisme officiel.

D'autre part, la place prépondérante qu'occupe la traduction au pays fait du Canada un lieu de prédilection pour dégager les liens existant entre traduction et culture, ce dernier terme étant pris dans son acception la plus large. À l'âge de l'électronique, les véhicules de la culture (populaire ou non) sont innombrables et omniprésents. Il n'est donc pas sans intérêt de s'interroger, par exemple, sur le contenu culturel des annonces publicitaires conçues en anglais dans les agences de Toronto ou de New York et traduites à l'intention des consommateurs francophones. Nombreux sont ceux qui jugent cette situation anormale. Maurice Watier, du Cercle des cadres de la publicité, est de ce nombre. Il y voit une grave atteinte à l'identité culturelle des Québécois.

La publicité en langue française publiée an Québec, écrit-il, est presque entièrement traduite de l'anglais - et le plus souvent, mal traduite. C'est pourquoi, en règle générale, la publicité, d'inspiration culturelle autre que la nôtre, nous dépersonnalise ${ }^{\mathrm{s}}$.

Quand on songe qu'au moins $70 \%$ des annonces de presse et télévisées diffusées au Québec sont des traductions, l'analyse attentive de leurs résonances culturelles peut déboucher sur des conclusions fort significatives. Il appartient donc à l'historien de la traduction de tenter de dégager les conséquences culturelles de la traduction publicitaire et de la traduction massive d'émissions télévisées américaines. A-t-on déjà cherché à savoir dans quelle mesure les traits culturels de la civilisation américaine s'infiltrent dans la culture canadienne-française par le canal de la traduction? Combien savent que quatre-vingt pour cent des bandes dessinées publiées dans les journaux du Québec sont des importations américaines, traduites bien entendu ?

Les considérations qui s'appliquent à la culture sont également valables pour la langue, culture et langue étant intimement liées. Lors d'une table ronde sur

8. Maurice Watier, cité par Augustin Turenne, Nous parlon (sic) francais (sic), Montréal, Les éd. la Presse, 1973, p. 17.

9. Jules Arbec, - Du dessin... à la bande dessinée ", le Devoir, 1er mai 1976, p. 18. 
l'évolution de la traduction au Canada, M. Jacques Poisson a exprimé un point de vue tout à fait pertinent à ce propos :

Au-delà d'un certain seuil, dit-il, la présence de la traduction tend à détruire la langue d'arrivée. On connaît les risques d'interférences qui ont été abondamment étudiés, mais on s'est moins arrêté à l'appauvrissement du français par l'absence d'utilisation des ressources qui ne sont pas suggérées par l'anglais. De même, faute d'un ressourcement original, ces références culturelles qui sous-tendent la vie d'une langue finissent par s'estomper, ce qui aboutit à une langue sans racine, artificielle, comme le latin au Moyen Age ${ }^{10}$.

Une langue largement alimentée de traduction peut-elle survivre et s'épanouir ou ne risque-t-elle pas un inévitable étiolement par asphyxie? L'étude diachronique, donc historique, des traductions peut apporter une réponse à cette question.

En somme, l'histoire de la traduction au Canada peut fournir des indications générales sur les rapports entretenus par les deux principaux groupes culturels du pays et sur l'influence de la civilisation américaine. Dans quelle mesure la traduction a-t-elle contribué et contribue-t-elle à briser l'isolement des "Deux solitudes $\gg$ ? Est-elle vraiment un facteur de rapprochement ? N'implique-t-elle pas par définition la présence d'un intermédiaire? Quelle est la valeur d'une communication par personnes interposées ? Est-ce surtout le Canada français qui a traduit le Canada anglais ou l'inverse? Toutes ces questions et combien d'autres demeurent encore sans réponse.

L'objet de l'ambitieux projet d'histoire décrit ci-dessus dans ses grandes lignes est de tenter d'apporter tout au moins quelques éléments de réponse à ces interrogations fondamentales sur le rôle de la traduction dans la société canadienne. Nous sommes un "peuple de traducteurs \$, mais sommes-nous aussi un peuple traduit ?

Jean Delisle

10. Jacques Poisson, * Table ronde sur l'́́volution de la traduction ", Meta, vol. XX, no 1 , mars 1975, p. 64. 